\title{
Fall prevention strategies in community-dwelling older adults aged 65 or over with type 2 diabetes mellitus: a systematic review and meta-analysis
}

\author{
Sujin Hwang ${ }^{a}$, Youngkeun Woo \\ ${ }^{a}$ Department of Physical Therapy, Division of Health Science, Baekseok University, Cheonan, Republic of Korea \\ ${ }^{\mathrm{b}}$ Department of Physical Therapy, College of Medical Science, Jeonju University, Jeonju, Republic of Korea
}

\begin{abstract}
Objective: Independent walking is the most essential prerequisite to maintain quality of life in older persons. The purpose of this review was to investigate the effect of fall prevention strategies on fall risk for type 2 diabetes mellitus (T2DM) within community-dwelling older adults aged 65 and over.
\end{abstract}

Design: A systematic review and meta-analysis.

Methods: PubMed and three other databases were searched up to October 31st, 2018 and randomized controlled trials (RCTs) evaluating fall prevention strategies for fall risk in persons who were 65 years of age or above with T2DM were included. The review extracted the following information from each study selected: first author's surname, published year, country, study population, type of intervention, intensity of intervention, comparison, measurement variables, additional therapy, summary of results, and mean and standard deviation from selected studies.

Results: This review selected fourteen RCTs with 460 older adults with diabetes mellitus. Of the 14 studies, the types of intervention used to improve the risk of falls were strengthening (5), aerobic exercises (2), multimodal exercises (4), one virtual reality exercise (1), whole body vibration with balance exercise (1), and Tai Chi exercise (1). Seven RCTs were eligible for the meta-analysis. Therapeutic interventions were more effective than the control group for the Timed Up-and-Go test $(-1.11 ; 95 \%$ CI, -1.82 to -0.41$)$ and the 6 -minute Walk Test $(-1.89 ; 95 \% \mathrm{CI},-8.33$ to 4.54$)$.

Conclusions: The results of the review suggest that interventions to prevent fall risk in older adults with T2DM should focus on strengthening, balance, aerobic, and multimodal exercises.

Key Words: Accidental falls, Aged, Diabetes mellitus

\section{Introduction}

Diabetes mellitus (DM) is a major public health problem and the prevalence of DM increases exponentially with age worldwide [1,2]. Recent systematic analysis of health examination surveys and epidemiological studies reported the global prevalence of DM to be 347 million in the year 2008 [3]. Previous studies have established the importance of physical exercise and fitness in older adults with DM and it is now well-established that regular exercise can prevent secondary impairments, such as increased risk of falls, cardiovascular problems, and peripheral neuropathy [4].

In the previous review of this systematic review, we identified the relationship between the risk of falls and type 2 diabetes mellitus (T2DM) in older adults who are 65 years of age or above. The results of the review reported that they have increased risk of falling caused by cognitive dysfunction, peripheral nerve dysfunction, visual impairment, and physical function level [5]. Chapman et al. [6] investigated the first systematic review and meta-analyses of exercise in-

Received: 23 October, 2018 Revised: 20 November, 2018 Accepted: 21 November, 2018

Corresponding author: Sujin Hwang (ORCID https://orcid.org/0000-0001-8471-0103)

Department of Physical Therapy, Division of Health Science, Baekseok University, 76 Munam-ro, Dongnam-gu, Cheonan 31065 , Republic of Korea Tel: 82-41-550-2309 Fax: 82-41-550-2829 E-mail: sujin928@gmail.com

(c) This is an Open-Access article distributed under the terms of the Creative Commons Attribution Non-Commercial License (http://creativecommons.org/licenses/ by-nc/4.0) which permits unrestricted non-commercial use, distribution, and reproduction in any medium, provided the original work is properly cited.

Copyright (๑ 2018 Korean Academy of Physical Therapy Rehabilitation Science 
terventions for the improvement of fall-related outcomes among older adults with DM, with the aim of quantifying the effectiveness of interventions, relative to control conditions and to assist in tailoring future interventions to meet the needs of the growing population of older adults with DM. They defined fall-related outcomes, fall rates, fall risks, static balance, functional performance with a dynamic balance component, functional performance with combined static/dynamic balance components, gait, and lower-limb strength [6]. They suggested that exercise interventions can improve certain fall-related outcomes among older adults with DM.

The purpose of the review was to investigate the effects of fall prevention strategies on risk of falls for T2DM with community-dwelling older adults aged 65 and over. Therefore, the review performed a systematic review of the literature to determine which fall prevention strategies have been shown to have positive effects on improving risk of falls in community-dwelling elderly persons with T2DM, and performed a meta-analysis of selected studies for quantitative syntheses.

\section{Methods}

The review was conducted in line with the Preferred Reporting Items for Systematic Reviews and Meta-Analyses (PRISMA) Statement for systematic reviews and metaanalysis. The search strategy of the review was performed by two researchers and one librarian. To analyze the effects of fall prevention strategies on risk of falls through qualitative and quantitative synthesis, the systematic review and meta-analysis were performed on Patient/Participants/ Population/Problem, Intervention, Comparison, Outcome with Timing, Setting Study Design.

\section{Search strategy}

The review protocol was registered on PROSPERO (registration number: CRD42018104967) based on the PRISMA. We also conducted the review in accordance with the checklist of the PRISMA. The review was conducted by four academic electronic databases including PubMed, EMbase, CINAHL, and PsycINFO for randomized controlled trials (RCTs) published up to October 1st, 2018. The search strategy was a combination of the following MeSH terms and related terms: (diabetes mellitus OR diabetic OR DM) AND (Falls OR Falling OR Accidental falls) AND (Prevention OR Therapy OR Exercise) AND (randomized controlled trials OR Randomized Clinical Trials). The search was restricted to studies on humans and those written in English only. In addition, the reference lists of all identified relevant publications were reviewed.

\section{Screening and eligibility of the selected studies}

After identifying the studies through searching the four databases, we screened by hand to remove duplicate studies from the reference lists of the selected studies. The article titles from the search were each reviewed independently by two authors. Titles were accepted if they contained the topics of DM, risks of falls or fall risk, fall prevention strategies, and older persons. In this review, fall risks were defined as factors including cognitive dysfunction, peripheral nerve dysfunction, visual impairment, and physical dysfunction, and fall prevention strategies were defined as physical exercise programs such as therapeutic intervention. The title and abstracts of the studies retrieved using the search strategy was screened independently by the review author to identify studies that potentially met the inclusion and exclusion criteria outlined above. The full text of these potentially eligible studies was retrieved and independently assessed for eligibility by the reviewers. This review included nine RCT for qualitative synthesis (Figure 1).

The inclusion criteria were as follows if: (1) the participants were 65 years of age and over; (2) the participants had a diagnosis of T2DM and were using anti-diabetic agents; and (3) RCT that evaluated the effect of fall prevention strategies on the risk of falls in community-dwelling elderly population. Studies were excluded if: (1) the article was written in languages other than English; (2) the study was not published as the full reports, such as case reports, commentaries, conference abstracts and letters to editors; (3) any other types of study design other than RCTs; (4) the patients had a diagnosis of type $1 \mathrm{DM}$; and (5) the participants were 64 years of age or less. The review also excluded studies if they did not provide data that allowed calculation of standard errors for effect estimates on risks of falls and if the estimates had not been adjusted for age.

\section{Data analysis}

All statistical analyses of the review were performed using RevMan 5.3 (http://ims.cochrane,org/revman). First, the review extracted information for assessment of the risk of bias including random sequence generation (selection bias), allocation concealment (performance bias), blinding of participants and personnel (performance bias), blinding of out- 


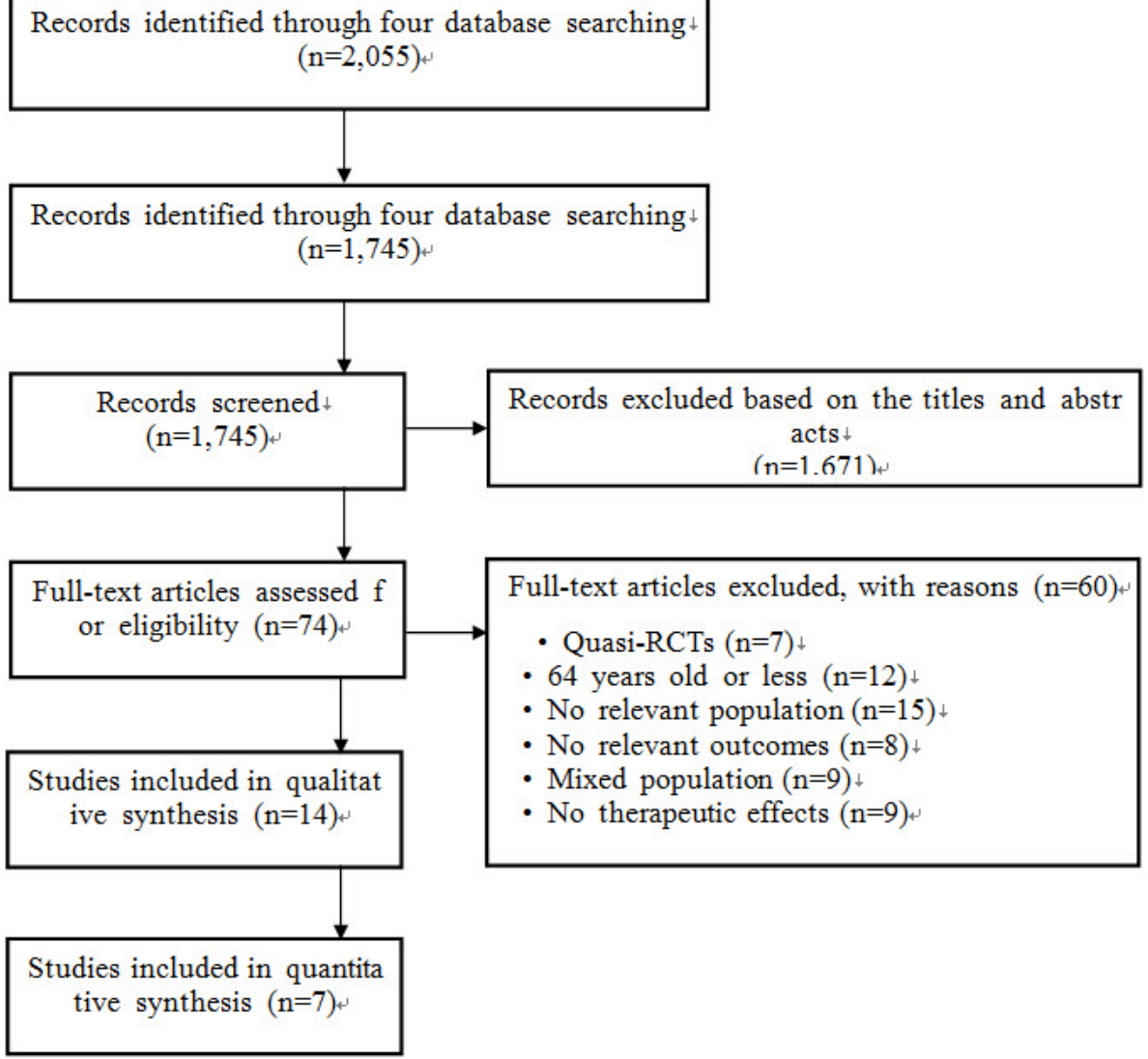

Figure 1. Flow diagram of included studies in the review. RCT: randomized controlled trial. come assessment (detection bias), incomplete outcome data (attrition bias), and selective reporting (reporting bias). Subsequently, the internal validity of selected RCTs was assessed. Mean and standard deviation values for each outcome were extracted for each group and pooled to obtain the mean difference (MD) and 95\% confidence intervals (CI). Heterogeneity was examined using Higgins $\mathrm{I}^{2}$-statistic. Heterogeneity of the pooled RCTs was divided into low level ( $\mathrm{I}^{2}$ of $25 \%$ to $50 \%$ ), moderate level ( $\mathrm{I}^{2}$ of values of $50 \%$ to $75 \%)$, and high level $(>75 \%)$. This review used fixed-effect models if $\mathrm{I}^{2}$ test was not significant ( $p$ for heterogeneity $<0.1$ ), but random effect models were used if it was significantly different.

\section{Results}

Literature search and characteristics of the included RCTs

Based on the initial search strategies, the review retrieved a total of 2,055 RCTs from four mainstream electronic databases and 1,745 records remained after duplicates were removed. Then, 1,671 articles of the 1,745 were excluded based on the title and abstracts. Seventy-four RCT full-text articles were assessed for eligibility and 60 full-text articles of the 74 articles were excluded, with reason; 12 RCTs with T2DM participants who were 64 years old or less, 7 Quasi-RCTs, 15 articles with no relevant population; 8 articles with no relevant outcomes, 9 articles with mixed population, and 9 articles with no therapeutic effects (Figure 1).

\section{Fall prevention strategies in 65 years or over commun- ity-dwelling persons with T2DM}

This review selected fourteen RCTs with 460 older adults with DM. Of the 14 studies, there were different types of intervention to improve fall risks [7-20]. There were 5 studies on strengthening [8-11,16], 2 on aerobic exercises [7,19], 4 on multimodal exercises $[12,13,17,18]$, one on virtual reality exercise [14], one on whole body vibration with balance exercise [14] and one on tai chi exercise [20]. The multimodal exercises involved one article which received strengthening exercise with balance exercises, a walking program and motivational telephone calls [12], one article which received multisensory exercises (eyes open versus closed, firm surface versus soft surface) [13], one article 
Table 1. Clinical information of included studies

$(\mathrm{N}=14)$

\begin{tabular}{|c|c|c|c|c|c|c|c|c|}
\hline Author, year & Country & $\begin{array}{l}\text { No. of } \\
\text { participants }\end{array}$ & Intervention & $\begin{array}{l}\text { Therapeutic } \\
\text { Intensity }\end{array}$ & Comparison & Outcome measures & $\begin{array}{l}\text { Additional } \\
\text { therapy }\end{array}$ & $\begin{array}{l}\text { Summary } \\
\text { of results }\end{array}$ \\
\hline Asa, 2012 & Sweden & 20 & $\begin{array}{l}\text { Aquatic } \\
\text { Ex.VO2max } \\
40 \%-70 \%\end{array}$ & $\begin{array}{l}24 \text { sessions, } \\
45 \mathrm{~min}\end{array}$ & No Ex. & $\begin{array}{l}6 \text { mWT, KE strength, } \\
\text { SF-36 }\end{array}$ & No mentioned & $\begin{array}{l}\text { More } \\
\text { improved }\end{array}$ \\
\hline $\begin{array}{l}\text { Brandon, } \\
2003\end{array}$ & USA & 31 & Strength Ex. & $\begin{array}{l}216 \text { sessions, } \\
60 \mathrm{~min}\end{array}$ & No mentioned & $\begin{array}{l}\text { TUG, } 50 \mathrm{ft} \mathrm{WT,} \mathrm{KE} \\
\text { strength }\end{array}$ & No mentioned & $\begin{array}{l}\text { More } \\
\text { improved }\end{array}$ \\
\hline Brooks, 2007 & USA & 62 & $\begin{array}{l}\text { Strength } \\
\text { Ex+standard } \\
\text { care }\end{array}$ & $\begin{array}{l}48 \text { sessions, } \\
45 \mathrm{~min}\end{array}$ & Standard care & $\begin{array}{l}\text { UBM strength, LBM } \\
\text { strength, M. quality, } \\
\text { M. fiber ratio }\end{array}$ & No mentioned & $\begin{array}{l}\text { More } \\
\text { improved }\end{array}$ \\
\hline $\begin{array}{l}\text { Dunstan, } \\
2002\end{array}$ & Australia & 36 & Resistance Ex. & $\begin{array}{l}72 \text { sessions, } \\
55 \mathrm{~min}\end{array}$ & $\begin{array}{l}\text { Aerobic } \\
\text { Ex.+stretching } \\
\text { Ex. }\end{array}$ & $\begin{array}{l}\text { Anthropometry, Body } \\
\text { composition, Muscle } \\
\text { strength, Resting BP, } \\
\text { Energy expenditure }\end{array}$ & No mentioned & $\begin{array}{l}\text { More } \\
\text { improved }\end{array}$ \\
\hline Hsieh, 2016 & Taiwan & 30 & Resistance Ex. & 36 sessions, & Usual care & $\begin{array}{l}\text { UE \& LE maximal M. } \\
\text { strength, M. oxygenation } \\
\text { response, TUG, } 1 \mathrm{mSTS} \\
\text { test, 5RSTS test, } \\
\text { Aerobic capacity }\end{array}$ & No mentioned & $\begin{array}{l}\text { More } \\
\text { improved }\end{array}$ \\
\hline Kruse, 2010 & USA & 79 & $\begin{array}{l}\text { Strength Ex., } \\
\text { Balance Ex., } \\
\text { Walking } \\
\text { program, } \\
\text { motivational } \\
\text { telephone calls }\end{array}$ & $\begin{array}{l}8 \text { sessions } \\
\text { with } \mathrm{PT}+3 \\
\text { sessions at } \\
\text { home }\end{array}$ & $\begin{array}{l}\text { Diabetes } \\
\text { self-care } \\
\text { instruction }\end{array}$ & $\begin{array}{l}\text { OLS, BBS, TUG, } \\
\text { Rt. DF strength, } 12 \\
\text { month falls rates }\end{array}$ & $\begin{array}{l}\text { Usual medical } \\
\text { care } \\
\text { Therapeutic } \\
\text { footwear }\end{array}$ & $\begin{array}{l}\text { More } \\
\text { improved }\end{array}$ \\
\hline Kutty, 2013 & Malaysia & 32 & Multisensory Ex. & $\begin{array}{l}18 \text { sessions, } \\
30 \mathrm{~min}\end{array}$ & No treatments & TUG, 6 mWT & $\begin{array}{l}\text { Usual leisure } \\
\text { activities }\end{array}$ & $\begin{array}{l}\text { More } \\
\text { improved }\end{array}$ \\
\hline Lee, $2013 \mathrm{a}$ & $\begin{array}{l}\text { Republic } \\
\text { of Korea }\end{array}$ & 64 & Virtual reality Ex. & $\begin{array}{l}20 \text { sessions, } \\
50 \mathrm{~min}\end{array}$ & Health education & $\begin{array}{l}\text { OLS, BBS, TUG, Gait } \\
\text { velocity and Cadence }\end{array}$ & No mentioned & $\begin{array}{l}\text { More } \\
\text { improved }\end{array}$ \\
\hline Lee, $2013 b$ & $\begin{array}{l}\text { Republic } \\
\text { of Korea }\end{array}$ & 60 & $\begin{array}{l}\text { WBV+balance } \\
\text { Ex. } \\
\text { Balance Ex. }\end{array}$ & $\begin{array}{l}12 \text { sessions, } \\
60 \mathrm{~min}\end{array}$ & No balance Ex. & $\begin{array}{l}\text { OLS, BBS, TUG, } \\
\text { postural sway, gait } \\
\text { velocity, cadence, falls } \\
\text { efficacy }\end{array}$ & No mentioned & $\begin{array}{l}\text { More } \\
\text { improved }\end{array}$ \\
\hline $\mathrm{Ng}, 2018$ & $\begin{array}{l}\text { Hong } \\
\text { Kong }\end{array}$ & 93 & Strengthening Ex. & $\begin{array}{l}20 \text { sessions, } \\
60 \mathrm{~min}\end{array}$ & $\begin{array}{l}\text { Usual daily } \\
\text { activities }\end{array}$ & SOT, TUG, SLST & Rhythmic Ex. & $\begin{array}{l}\text { More } \\
\text { improved }\end{array}$ \\
\hline Tan, 2012 & China & 30 & $\begin{array}{l}\text { Aerobic } \\
\text { Ex.+Resistance } \\
\text { Ex. }\end{array}$ & $\begin{array}{l}18 \text { sessions, } \\
60 \mathrm{~min}\end{array}$ & No mentioned & $\begin{array}{l}6 \mathrm{mWT} \text {, DF peak torque, } \\
\text { PF peak torque }\end{array}$ & No mentioned & $\begin{array}{l}\text { More } \\
\text { improved }\end{array}$ \\
\hline $\begin{array}{l}\text { Taveggia, } \\
2013\end{array}$ & Italy & 27 & Multimodal Ex. & $\begin{array}{l}20 \text { sessions, } \\
60 \mathrm{~min}\end{array}$ & $\begin{array}{l}\text { Standard care } \\
\text { group }\end{array}$ & $\begin{array}{l}6 \text { mWT, } 10 \text { mWT, FIM, } \\
\text { Tinetti POMA, REE, } \\
\text { RR }\end{array}$ & No mentioned & $\begin{array}{l}\text { More } \\
\text { improved }\end{array}$ \\
\hline Tessier, 2000 & Canada & 39 & Aerobic Ex. & $\begin{array}{l}48 \text { sessions, } \\
60 \mathrm{~min}\end{array}$ & No mentioned & $\begin{array}{l}\text { Treadmill test, QOL, } \\
\text { Attitudes questionnaire }\end{array}$ & No mentioned & $\begin{array}{l}\text { More } \\
\text { improved }\end{array}$ \\
\hline Tsang, 2008 & Australia & 37 & Tai Chi & $\begin{array}{l}32 \text { sessions, } \\
60 \mathrm{~min}\end{array}$ & Sham Ex. & $\begin{array}{l}\text { Glucose metabolism, } \\
\text { BMI, Habitual physical } \\
\text { activity }\end{array}$ & No mentioned & $\begin{array}{l}\text { More } \\
\text { improved }\end{array}$ \\
\hline
\end{tabular}

Ex: exercise, 6 mWT: 6 minute walk test, KE: knee extension, TUG: timed up-and-go test, WT: walk test, UBM: upper body mass, LBM: lower body mass, M: muscle, BP: blood pressure, UE: upper extremity, LE: lower extremity, 1 mSTS test: 1 minute sit-to-stand test, 5RSTS test: 5 repetition of sit-to-stand test, PT: physical training, OLS: one leg stance, BBS: Berg balance scale, DF: dorsiflexion, WBV: whole body vibration, PF: plantarflexion, $10 \mathrm{mWT}$ : 10 meter walk test, SLST: single-leg stance test, SOT: sensory organization test, POMA: performance-oriented mobility assessment, REE: resting energy expenditure, RR: respiratory rate, QOL: quality of life, BMI: body mass index.

which included treadmill training with dynamometer and dynamic balance platform training [18], and one article which inclueds aerobic exercise with resistance exercise [17]. Another article randomly allocated three different groups including whole body vibration with balance exercises, balance exercises, and control groups (Table 1).

The selected articles used variable outcome measures to assess the therapeutic effects such as aerobic capacity 
(6-minute walk test, energy expenditure, muscle oxygenation response, 1-minute sit-to-stand, 50-foot walk test), muscle strength (knee extensor strength, upper body mass strength, lower body mass strength, dorsiflexion peak torque, plantarflexion peak torque), balance (one-legged stance, Berg Balance Scale, 5-times sit-to-stand, Timed Up-and-Go test, Tinetti performance-oriented mobility assessment, postural sway), gait (gait velocity, cadence), muscle physiology (muscle quality, muscle fiber ratio, anthropometry, body composition) and others (SF-36, resting blood pressure, glucose metabolism, habitual physical activity) (Table 1).

\section{Risk of bias in all included RCTs}

All selected RCTs showed low risk in incomplete outcome data (attrition bias) and selective reporting (reporting bias). One of the fourteen RCTs showed unclear risk of bias in random sequence generation (selection bias) and allocation concealment (selection bias). Six of the fourteen RCTs showed unclear risk of bias in blinding of participants and personnel (performance bias) and blinding of the outcome assessment (detection bias). Only one of the fourteen RCTs showed high risk of bias in blinding of participants and personnel (performance bias) and blinding of the outcome assessment (detection bias) (Figure 2).
Association between Timed Up-and-Go test and Strengthening exercise

Four RCTs involving 233 diabetic patients reported the effects of strengthening exercise on the Timed Up-and-Go test. Strengthening exercise improved Timed Up-and-Go test scores (MD, $-1.11 ; 95 \% \mathrm{CI},-1.82$ to -0.41 ) compared with the control group in community-dwelling older persons with T2DM. A fixed-effect model was selected because significant heterogeneity $\left(\mathrm{chi}^{2}, 2.37 ; \mathrm{I}^{2}, 0 \% ; p=0.50\right)$ was not observed (Figure 3).

\section{Association between the 6-minute walk test and multi-} modal exercise

Three RCTs involving 89 diabetic patients reported the effects of multimodal exercise on the 6-minute walk test. Multimodal exercise improved endurance (MD, - 1.89; $95 \% \mathrm{CI},-8.33$ to 4.54 ) compared with the control group in community-dwelling older persons with T2DM. A random-effects model was selected because significant heterogeneity (chi $\left.{ }^{2}, 20.19 ; \mathrm{I}^{2}, 90 \% ; p=0.56\right)$ was not observed (Figure 4).

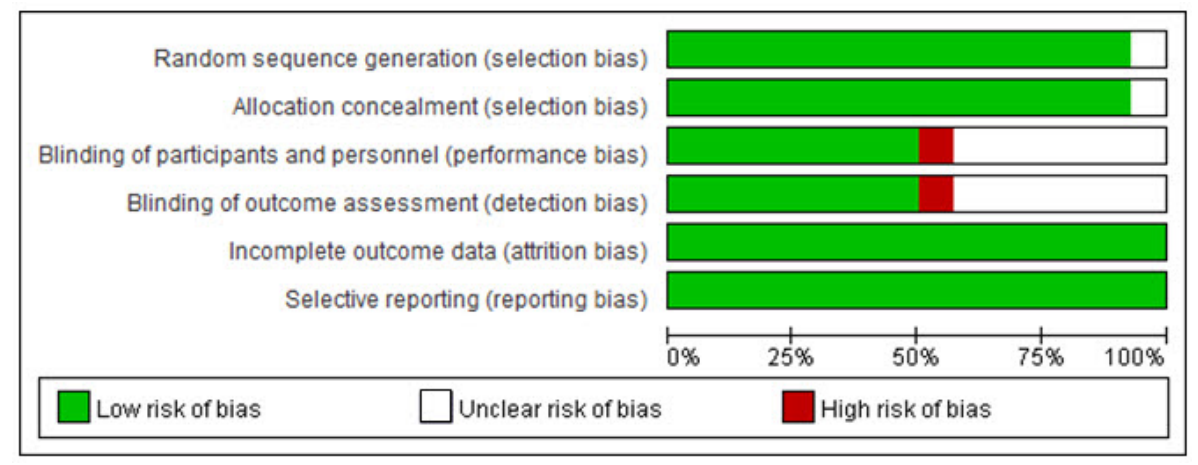

Figure 2. Risk of bias graph of the systematic review.

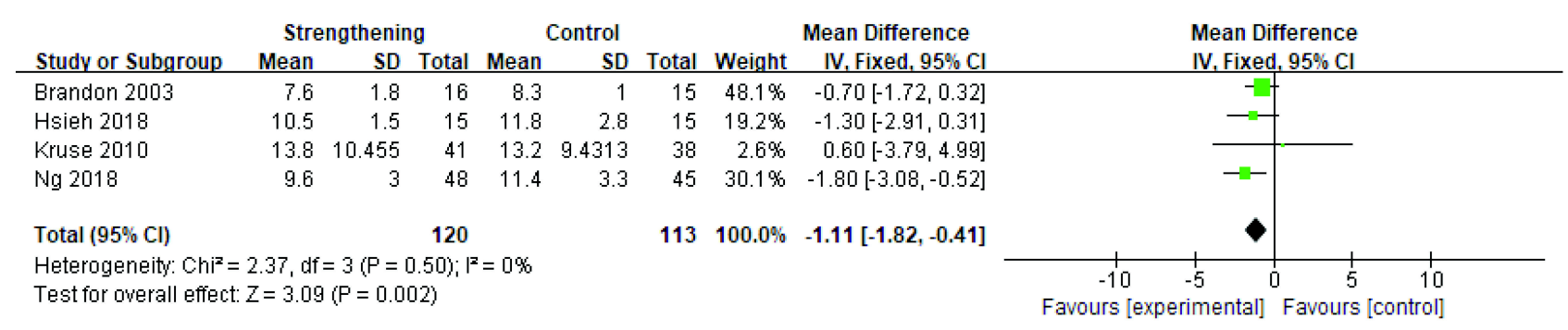

Figure 3. Forest plot of timed up-and-go test between strengthening exercise and control group. 


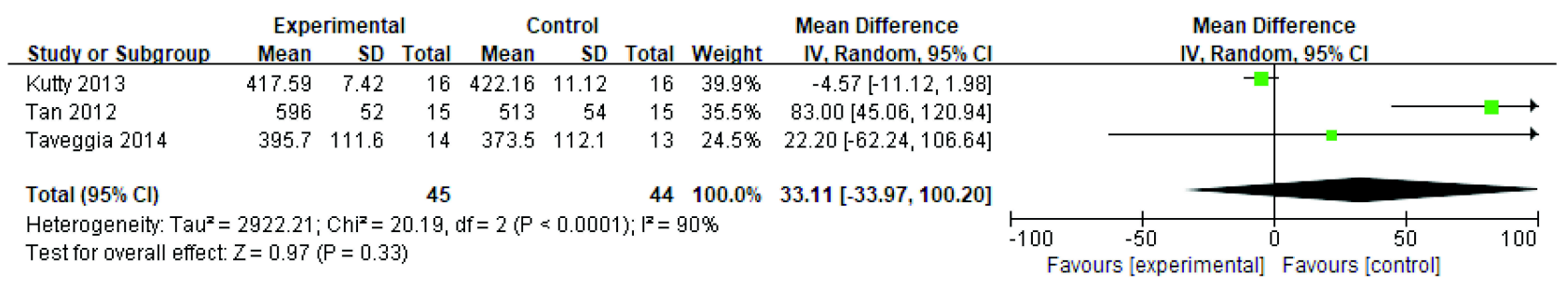

Figure 4. Forest plot of 6-minute walk test between multimodal exercise and control group.

\section{Discussion}

This objective review investigated the effects of fall prevention strategies on risk of falls for T2DM in community-dwelling older adults aged 65 and over. As a result of all included studies, the most common fall prevention strategies were lower extremity strength training, multimodal exercises, aerobic exercises, and balance training. Of the 14 included RCTs, they used outcome measures such as muscle strength, static and dynamic balance, and kinematic characteristics of gait. Strength exercise and multimodal exercise improved postural control and endurance in community-dwelling older persons with T2DM.

Previous review of this research project identified that the risk factors of falls were impaired cognitive function, peripheral nerve dysfunction, visual impairment, and physical dysfunction in community-dwelling persons who had 65 years of age or above with T2DM [5]. This study investigated therapeutic exercises as a fall prevention strategy to improve the risk of falls in community-dwelling older adults with T2DM. According to several studies, therapeutic exercise is beneficial for managing T2DM [21-23]. A recent review reported that exercise has known benefits on the mechanisms linking T2DM to dementia, although there are very few RCTs [23]. Grewal et al. [21] investigated the effect of sensor-based interactive balance training on postural stability and daily physical activity in older adults with diabetes. The sensor-based balance training which focused on shifting weight and crossing virtual obstacles, improved postural balance in diabetics with peripheral neuropathy [21]. In the review, two RCTs reported therapeutic effects on postural stability and physical activity compared to no balance training or sham exercise. Geirsdottir et al. [22] investigated muscle mass and physical function before and after a resistance exercise program in persons with prediabetes or T2DM. They reported that a 12-week resistance exercise program improved muscle strength and muscle function in persons with T2DM to a similar extent to elderly persons who were healthy and prediabetic. The systematic analysis of this review showed that the most common exercise to improve fall risk was strengthening exercises. Five RCTs conducted resistance exercise to improve risk of falls and two RCTs which involved resistance exercise combined with another exercise. The RCTs showed greater improved after strengthening exercises than the control group.

The review also investigated multimodal exercises and found that they improved the risk of falls in T2DM with community-dwelling older adults aged 65 and over. The results of the review suggested that strengthening and multimodal exercises could be a fall prevention strategy to improve the risk of falls in community-dwelling older adults aged 65 and over with T2DM. Fall prevention strategies induced by strengthening and multimodal exercise may improve the risk of falls for T2DM. Future studies should address the association risk of falls and the duration, intensity and frequency of strengthening exercise for T2DM, and should address proper types that combine multimodal exercises. Since the review involved community-dwelling older adults aged 65 and over with T2DM, it is difficult to generalize the results other than to this particular population. A recent review suggested that risk of falls were related with cognitive dysfunction, peripheral nerve dysfunction, visual impairment, and physical function level. This review reported improvements in postural balance and gait performance, but not on cognitive dysfunction and visual impairment. Therefore, future studies should address the therapeutic effects of these exercises on cognitive dysfunction and visual impairment for elderly adults with T2DM.

\section{Acknowledgements}

This research is being supported by the Basic Science Research Program through the National Research Foundation of Korea (NRF) funded by the Ministry of Education 
(2018050771).

\section{Conflict of Interest}

The authors declared no potential conflicts of interest with respect to the authorship and/or publication of this article.

\section{References}

1. Gravesande J, Richardson J. Identifying non-pharmacological risk factors for falling in older adults with type 2 diabetes mellitus: a systematic review. Disabil Rehabil 2017;39:1459-65.

2. El-Menyar A, Mekkodathil A, Al-Thani H. Traumatic injuries in patients with diabetes mellitus. J Emerg Trauma Shock 2016;9: 64-72.

3. Danaei G, Finucane MM, Lu Y, Singh GM, Cowan MJ, Paciorek $\mathrm{CJ}$, et al. National, regional, and global trends in fasting plasma glucose and diabetes prevalence since 1980: systematic analysis of health examination surveys and epidemiological studies with 370 country-years and 2.7 million participants. Lancet 2011;378: 31-40.

4. Ites KI, Anderson EJ, Cahill ML, Kearney JA, Post EC, Gilchrist LS. Balance interventions for diabetic peripheral neuropathy: a systematic review. J Geriatr Phys Ther 2011;34:109-16.

5. Hwang S. Risk of falls in community-dwelling older adults aged 65 or over with type 2 diabetes mellitus: a systematic review. Korean Acad Phys Ther Rehab Sci 2018;7:139-45.

6. Chapman A, Meyer C, Renehan E, Hill KD, Browning CJ. Exercise interventions for the improvement of falls-related outcomes among older adults with diabetes mellitus: a systematic review and meta-analyses. J Diabetes Complications 2017;31: 631-45.

7. Asa C, Maria S, Katharina SS, Bert A. Aquatic exercise is effective in improving exercise performance in patients with heart failure and type 2 diabetes mellitus. Evid Based Complement Alternat Med 2012. doi:10.1155/2012/349209.

8. Brandon LJ, Gaasch DA, Boyette LW, Lloyd AM. Effects of long-term resistive training on mobility and strength in older adults with diabetes. J Gerontol A Biol Sci Med Sci 2003;58:740-5.

9. Brooks N, Layne JE, Gordon PL, Roubenoff R, Nelson ME, Castaneda-Sceppa C. Strength training improves muscle quality and insulin sensitivity in Hispanic older adults with type 2 diabetes. Int J Med Sci 2006;4:19-27.

10. Dunstan DW, Daly RM, Owen N, Jolley D, De Courten M, Shaw $\mathrm{J}$, et al. High-intensity resistance training improves glycemic control in older patients with type 2 diabetes. Diabetes Care
2002;25:1729-36.

11. Hsieh PL, Tseng CH, Tseng YJ, Yang WS. Resistance training improves muscle function and cardiometabolic risks but not quality of life in older people with type 2 diabetes mellitus: a randomized controlled trial. J Geriatr Phys Ther 2018;41:65-76.

12. Kruse RL, Lemaster JW, Madsen RW. Fall and balance outcomes after an intervention to promote leg strength, balance, and walking in people with diabetic peripheral neuropathy: "feet first" randomized controlled trial. Phys Ther 2010;90:1568-79.

13. Kutty NA, Majida NAL. Effects of multisensory training on balance and gait in persons with type 2 diabetes: a randomised controlled trial. Diabil CBR Inclu Develop 2013;24:79-91.

14. Lee $\mathrm{S}$, Shin $\mathrm{S}$. Effectiveness of virtual reality using video gaming technology in elderly adults with diabetes mellitus. Diabetes Technol Ther 2013;15:489-96.

15. Lee K, Lee S, Song C. Whole-body vibration training improves balance, muscle strength and glycosylated hemoglobin in elderly patients with diabetic neuropathy. Tohoku J Exp Med 2013;231: 305-14.

16. Ng TK, Kwan RLC, Lo SK, Cheing GL. A tailor-made exercise program for improving balance and mobility in older adults with type 2 diabetes. J Gerontol Nurs 2018;44:41-8.

17. Tan S, Li W, Wang J. Effects of six months of combined aerobic and resistance training for elderly patients with a long history of type 2 diabetes. J Sports Sci Med 2012;11:495-501.

18. Taveggia G, Villafañe JH, Vavassori F, Lecchi C, Borboni A, Negrini S. Multimodal treatment of distal sensorimotor polyneuropathy in diabetic patients: a randomized clinical trial. J Manipulative Physiol Ther 2014;37:242-52.

19. Tessier D, Ménard J, Fülöp T, Ardilouze J, Roy M, Dubuc N, et al. Effects of aerobic physical exercise in the elderly with type 2 diabetes mellitus. Arch Gerontol Geriatr 2000;31:121-32.

20. Tsang T, Orr R, Lam P, Comino E, Singh MF. Effects of Tai Chi on glucose homeostasis and insulin sensitivity in older adults with type 2 diabetes: a randomised double-blind sham-exercise-controlled trial. Age Ageing 2008;37:64-71.

21. Grewal GS, Schwenk M, Lee-Eng J, Parvaneh S, Bharara M, Menzies RA, et al. Sensor-based interactive balance training with visual joint movement feedback for improving postural stability in diabetics with peripheral neuropathy: a randomized controlled trial. Gerontology 2015;61:567-74.

22. Geirsdottir OG, Arnarson A, Briem K, Ramel A, Jonsson PV, Thorsdottir I. Effect of 12-week resistance exercise program on body composition, muscle strength, physical function, and glucose metabolism in healthy, insulin-resistant, and diabetic elderly Icelanders. J Gerontol A Biol Sci Med Sci 2012;67:1259-65.

23. Callisaya M, Nosaka K. Effects of exercise on type 2 diabetes mellitus-related cognitive impairment and dementia. J Alzheimers Dis 2017;59:503-13. 